\title{
Single Life Time Cytological Screening in High Risk Women as an Economical and Feasible Approach to Control Cervical Cancer in Developing Countries Like India
}

\author{
Jata Shankar Misra ${ }^{1}$, Anand Narain Srivastava ${ }^{1 *}$, Vinita Das $^{2}$
}

\begin{abstract}
In view of funding crunches and inadequate manpower in cytology in developing countries like India, single lifetime screening for cervical cancer has been suggested. In this study, an attempt was made to identify high risk groups of women for this screening to make it more effective for early detection. Cytological data were derived from the ongoing routine cervical cytology screening program for women attending Gynaecology Out Patient Department of Queen Mary's Hospital of K.G.Medical University, Lucknow, India during a span of 35 years (April 1971 - December 2005). Cervical smears in a total of 38,256 women were cytologically evaluated. The frequencies of squamous intraepithelial lesions of cervix (SIL) and carcinoma cervix were found to be $7.0 \%$ and $0.6 \%$, respectively, in the series. Predisposing factors related to cervical carcinogenesis were analyzed in detail to establish the most vulnerable groups of women for single life time screening. The incidence of SIL and carcinoma cervix was found to be maximal in women above the age of $\mathbf{4 0}$ years irrespective of parity and in multiparous women (with three or more children) irrespective of age. The incidence of cervical cytopathologies was significantly higher in symptomatic women, the frequency of SIL being alarmingly higher in women complaining of contact bleeding and that of carcinoma cervix in older women with postmenopausal bleeding. It is consequently felt that single life time screening must include the three groups of women delineated above. Such selective screening appears to be the most economical, cost effective and feasible approach to affordably control the menace of cervical cancer in developing countries like India.
\end{abstract}

Keywords: Cervical cancer - SIL - single life time screening - high risk group - India

Asian Pac J Cancer Prev, 16 (3), 859-862

\section{Introduction}

The carcinoma cervix has still been rated as most dreaded disease affecting women in India accounting for a high mortality rate. It is estimated that about one lakh women develop cancer cervix each year inspite ofGovernment attention in this matter and intervention at a large scale specially in rural population is urgently needed. The main factors contributing to a high burden of cervical cancer over the years in India are increase in the population size with substantial increase in the proportion of elderly population, urbanization and globalization (D'Souza et al 2013). Cervical cytological screening has been found very effective in checking the menace of carcinoma cervix in developing countries and infact in some of these countries the incidence and mortality from the disease have been minimized to as much as $80 \%$ extent (Miller 2000).

Important association is seen between screening program for Pap smear and decreasing rate of cervical carcinoma. Hence need is felt for increasing knowledge of women regarding the risk factor of cervical carcinoma and motivate them for regular check-up (Karim Zarchi et al, 2010) In a cohort study in rural setting in south India, women of increasing age with many pregnancies and no education were found to be at significantly increased risk of cervical cancer. Public awareness through education and improvement in living standard can play an important role in reducing the higher incidence of cervical cancer in India. There is urgent need of formulating public health policy for increasing awareness and implementation of cervical cancer screening programmes (Thulaseedharan et al 2012). Cervical cancer awareness is higher in urban women in India as in a study of slum areas of Mumbai approximately $40 \%$ of women were aware of cervical cancer and Pap smear test (Domta et al, 2012). Further overall acceptance and satisfaction were encouraging with mobile cancer screening program in these areas and such a facility can act as an important tool in the cancer prevention and control in low socio-economic group (Kumar et al 2011).

The other risk factors of cervical cancer suggested by investigators in different Asian countries were early age 
marriage (Karim Zarchi et al., 2010, Kritpetchatrat et al., 2012) smoking characteristics of partners and interval between menache and first sexual intercourse (Natphopsuk et al., 2012), HPV infection, menopause and age at first child birth (Whang et al., 2013), educational level and marital status of women (Baker et al., 2013). Fear for examination, illiteracy, lack of awareness, poor quality of services and low income have been found negative factors for cancer prevention and interventions are essential to overcome these barriers (Kushawarz et al., 2011, Ghutibi et al., 2012; Baker et al., 2013; Choi et al., 2013; Sun et al.,2013). Other identified weakness which affect cervical cancer program are poor acceptance by women, lack of commitment by health workers, limited resources and competing needs (Abdullah et al., 2010; Budkaew et al., 2014). There is urgent need for improvement in basic education regarding cervical cancer screening for young and poorly educated women and improved outreach for follow-up is also essential to effectively control cervical cancer (Wang et al., 2012). In a community based screening of cervical cancer in a rural ethnically Muslim community of Kashmir, no case of cervical dysplasia and carcinoma cervix was found despite the presence of risk factors of high parity, at early age of marriage and early child birth after marriage. This indicates that socio-cultural factors like minimal promiscuity and male circumcision play important role in the low prevalence of carcinoma cervix (Yasmin et al., 2010).

Human papilloma virus (HPV) has been widely implicated in cervical carcinogenesis. In fact, HPV-DNA testing has replaced conventional Pap smear screening in America and other western countries. HPV testing provides better protection against cervical cancer than cytology but requires extra repeated testing (Lynge et al., 2014). A high load of high risk-HPV was the main predictor for CIN1 and II and HPV testing could be used as CIN 2 screening taking into account the verified risk factors like married status with number of sexual partners, active and passive smoking and age at sexual debut (Lee et al., 2014). The infection status and predominant genotype distribution of HPV among Chinese patients with mucopurulent cervicits and cervical cancer in Hanjhou has revealed that the overall prelevance of HPV infection was $84.4 \%$ in the cervical cancer group, $51.9 \%$ in mucopurulent cervicits group and only $16.7 \%$ in the control group. The predominant genotype detected in all three groups was the oncogenic variant HPV 16 followed by HPV 58. (Shen et al., 2013). HPV 16 was also found most prevalent HPV type followed by HPV 58 and 18 in studies from North Western Thailand (Natphophuk et al, 2011) and Vietnam (Vu et al., 2012).

Though the Pap test have been outdated in developed countries like America and have been replaced by HPV - DNA testing but the high expenditure involved in the procedure still eludes the developing countries in adopting this technique. The fund crunch and paucity of manpower in cytology have resulted in not even providing pap smear cover to every women one time in a year. Keeping all these factors in mind, cost analysis of pap smear on annual basis have been estimated and among different strategies formulated, the most feasible alternative have been found to plan single life time screening after 45 year of age for which $1.2 \%$ of the total annual health outlay of the country would be required and approx. $20 \%$ of the lives of women could be saved (Prabhakar, 1992). Routine cytological screening is in progress at Queen Mary's Hospital of K.G. Medical University from April 1971 and till December 2005 , a total of 38,256 women have been cytologicaly evaluated. The concept of single life time screening have been modified in accordance with our findings and broad coverage of women have been suggested.

\section{Materials and Methods}

During 35 years of routine cytological screening starting from April 1971, cervical smears of a total of 38,256 women have been examined till December. 2005. The age of the patients ranged from 16 to 70 years and parity from nulliparous to more than 3 children. Emphasis was made to screen those women who presented some gynecological symptoms or who showed some lesions on the cervix on the clinical examination. In all women prior to bimanual examination, a scrape smear was taken from the squamocolumnar junction of the cervix and immediately fixed in absolute alcohol and later stained according to Papanicalaou's technique. The smear were graded according to WHO classification of 1973 till 1992 after which Bethesda system of reporting the cervical diagnosis was followed. All the previous cases reported prior to 1992 have been reorganized accordingly. A routine cervical biopsy was taken in all squamous intraepithelial lesions of cervix (SIL) and frank carcinoma cervix cases.

\section{Results}

The cytological findings in the 38,256 women revealed epithelial cell abnormalities in $7.6 \%$ of cases ( 2853 cases). Of these 2853 cases, 2623 were SIL cases (7.0\%) and the remaining 230 cases were of frank carcinoma cervix (0.6\%). Of the 2623 SIL cases, 2013 (5.2\%) were LSIL and remaining 610 (1.6\%) were HSIL cases. The 2013 LSIL cases comprised of 1821 cases of mild dysplasia (4.7\%) and 192 condylomas (HPV-0.5\%). The 610 cases of HSIL comprised of 565 cases of moderate dysplasia $(1.6 \%)$ and 45 cases of severe dysplasia $(0.1 \%)$.

Predisposing factors related to cervical carcinogenesis such as age, parity and gynaecological symptoms have been analysed in detail in SIL and frank carcinoma cases diagnosed and the findings are presented in the Tables I, II and III.

As regard age (Table 1), the frequency of SIL and cancer cervix showed progressive rise with increasing age and the maximum frequency was seen in older women beyond 40 years of age (SIL-9.6\% and carcinoma cervix-1.2\%)

Parity also showed similar trend as a progressive increase in SIL and carcinoma cervix cases were seen with increasing parity (Table 2). The increase was more pronounced and statiscally highly significant between para 2 and para 3 and above $(\mathrm{p}<0.10)$.

The incidence of cervical cytopathologies has also been analyzed in detail in symptomatic women with 
Single Life Time Cytological Screening in High Risk Women in Developing Countries Like India

Table 1. Relation of Cervical Cytopathologies with age

\begin{tabular}{lrrc}
\hline Age Group & $\begin{array}{r}\text { No. of } \\
\text { Cases }\end{array}$ & \multicolumn{1}{c}{$\begin{array}{c}\text { SIL } \\
\text { Incidence }\end{array}$} & $\begin{array}{c}\text { Carcinoma } \\
\text { Cervix Incidence }\end{array}$ \\
\hline$<20$ years & 826 & $28(3.4 \%)$ & ---- \\
$21-30$ yrs. & 10,365 & $354(3.4 \%)$ & $8(0.07 \%)$ \\
$31-40$ yrs. & 12,819 & $860(6.1 \%)$ & $48(0.3 \%)$ \\
$>40$ years & 14,246 & $1,381(9.6 \%)$ & $174(1.2 \%)$ \\
\hline
\end{tabular}

Table 2. Relation of Cervical Cytopathologies with parity

\begin{tabular}{lrrc}
\hline Age Group & $\begin{array}{r}\text { No. of } \\
\text { Cases }\end{array}$ & $\begin{array}{r}\text { SIL } \\
\text { Incidence }\end{array}$ & $\begin{array}{c}\text { Carcinoma } \\
\text { Cervix Incidence }\end{array}$ \\
\hline Nulliparous & 872 & $32(3.6 \%)$ & $2(0.2 \%)$ \\
I & 2,451 & $134(5.4 \%)$ & $6(0.2 \%)$ \\
II & 11,353 & $669(5.8 \%)$ & $24(0.2 \%)$ \\
III and above & 23,580 & $1,788(7.5 \%)$ & $198(0.8 \%)$ \\
\hline
\end{tabular}

Table 3. Relation of Cervical Cytopathologies with Gynaecological Symptoms

\begin{tabular}{lrrc}
\hline Age Group & $\begin{array}{r}\text { No. of } \\
\text { Cases }\end{array}$ & $\begin{array}{c}\text { SIL } \\
\text { Incidence }\end{array}$ & $\begin{array}{c}\text { Carcinoma } \\
\text { Cervix } \\
\text { Incidence }\end{array}$ \\
\hline Menorragia & 1298 & $92(7.1 \%)$ & $9(0.4 \%)$ \\
Contact bleeding & 234 & $58(24.7 \%)$ & $1(0.4 \%)$ \\
Posrmenopausal bleeding & 295 & $23(7.7 \%)$ & $9(3.1 \%)$ \\
Vague pain in lower abdomen & 3173 & $260(8.1 \%)$ & $3(0.09 \%)$ \\
\hline Total & 9017 & $788(8.7 \%)$ & $58(0.6 \%)$ \\
\hline Asymptomatic women & 29239 & $1835(6.1 \%)$ & $172(0.5 \%)$
\end{tabular}

individual symptoms (Table 3). The incidence of SIL and carcinoma cervix was found to be significantly higher in symptomatic women than in the asymptomatic women (SIL-8.7\% as against $6.1 \%$ and carcinoma cervix- $0.6 \%$ as against $0.5 \%$ ). Though the incidence of SIL and Carcinoma Cervix was higher with all symptoms but the incidence of SIL was alarmingly higher in women complaining of contact bleeding (24.7\%) and that of carcinoma cervix in older women with postmenopausal bleeding (3.1\%).

As suggested earlier, under Indian conditions single life time screening seems to be the most feasible strategy for control of cervical cancer. WHO (1986) has recommended screening at 45 years of age as the most effective approach which may yield detection of about $20 \%$ of total cancer cases. Our experience in this field for last 35 years suggest for a more broad coverage to include following groups of women

1) As our study revealed $67.8 \%$ of the total SIL and $85.2 \%$ of total carcinoma cervix cases occurring in multiparous women of high parity with three or more children, it is felt that high parity group should be screened irrespective of age atleast once in their lifetime to detect any abnormal cytopathology. In fact $59.5 \%$ of the total cases screened belonged to this group.

2) Further our study also showed cervical cytopathologies occurring in older women beyond 40 years of age $(52.1 \%$ of total SIL and $77.2 \%$ of the total carcinoma cervix cases). Hence it is suggested that older women above the age of 40 years should be screened irrespective of parity once in their lifetime to detect pre- cancer and cancer cases. In the present series, $30.6 \%$ of the total cases screened were in this group.

3) The incidence of cervical cytopathologies was higher with all symptoms but the incidence of SIL was alarmingly higher in women complaining of contact bleeding and that of carcinoma cervix in older women with postmenopausal bleeding. Consequently it is felt that all symptomatic women specially those complaining of contact bleeding and postmenopausal bleeding should be included for single life time screening.

\section{Discussion}

Due to fund crunch and paucity of manpower in cytology in our country, a single Pap smear examination during life time of women may detect early cases of cervical cancer and may save many lives, specially in rural population where only basic medical facilities are available we have identified three high risk groups for this purpose. Our findings suggest that women of high parity (with three or more children), older women beyond 40 years of age irrespective of parity and all symptomatic women specially those complaining of contact bleeding or postmenopausal bleeding should be screened at least once in their lifetime to detect any onset of precancerous changes in the cervix. Our previous communications have also recommended this approach which is more suitable under low settings for developing countries like ours (Misra et al., 2004; 2007).

Currently AgNOR pleomorphism have been reported increasing with disease severity in cervical carcinogenesis (Rowlands 1988, Alarcon-Romero et al., 2009). We have also found pleomorphic dots showing rise with increasing grade of SIL and in frank carcinoma (Srivastava et al., 2013). Further we have been able to follow some low grade SIL cases with high and low mean counts of the pleomorphic dots and have seen that approximately $90 \%$ of SIL cases with high mean counts either showed persistence of the lesion or the LSIL progressed to a higher grade (Misra et al., 2009). Hence AgNOR counts could be useful in predicting high risk cases among the SIL cases detected. It is felt that if all the SIL cases diagnosed during single life time screening are subjected to AgNOR counts estimation, high risks cases among them could be segregated and followed regularly after adequate treatment to rule out the progression of the lesion. Our suggestion assumed importance from the report of Alarcon-Romero et al. (2009) that a correlation exist between AgNOR pleomorphism and high risk HPV infection. These authors have suggested that during progression of the lesion, HPV induces progressive increase in cellular proliferation and presence of pleomorphic AgNOR dots are products of cellular alteration that are not only related to viral integration with infected cells DNA but also the progression of the lesion. AgNOR counts could therefore easily replace highly expensive HPV DNA testing to find out high risks SIL cases for follow up for ascertaining the progression of the lesion of the disease. Any cytological surveillance program with this approach would definitely yield fruitful results in controlling the incidence of carcinoma cervix. This arrangement would be very 


\section{Jata Shankar Misra et al}

suitable for developing countries like India where due to fund shortage; Government is not able to afford expensive HPV DNA testing. Pap smear examination combined with AgNOR estimation is cheap and inexpensive and less time consuming and hence appears to be economical and feasible approach to control the incidence of cervical cancer and associated mortality and is affordable to developing countries like India.

\section{References}

Abdullah F, Su TT (2010). Enhancement of cervical cancer screening program in Malaysia: A qualitative study. Asian Pac J Cancer Prev, 11, 1359-66.

Alarcón-Romero Ldel C, Illades-Aguiar B, Flores-Alfaro E, et al (2009). AgNOR pleomorphism association with squamous intraepithelial lesions and invasive carcinoma with HPV infection. Salud Publica Mex, 51, 134-140.

Baker, M, Guler,H, Evili,F,Demiel, G. et al.(2013). Determining knowledge and attitude regarding gynaecological cancer prevention. Asian Pac J Cancer Prev, 14, 6055-9

Budkaew J, Chumorthavy P, (2014). Factors associated with decision to attend cervical cancer screening among women aged 30-60 years in Chatapadund Contracting Medical Unit, Thailand. Asian Pac J Cancer Prev, 15, 4903-7.

Domta B, Begum S, Nair S, Mali BN, et al (2012). Awareness of cervical cancer among couples in slum areas of Mumbai. Asian Pac J Cancer Prev, 13, 4901-3.

D'Souza, ND, Murthy NS, Aras RY (2013). Projection of cancer incident cases for India-2026. Asian Pac J Cancer Prev, 14, 4379-86.

Karim Zarchi, M,Akhvan, A, Gholmi H, et al (2010). Evaluation of cancer risk factors in women referred to Yazd Iran hospital from 2002-2009. Asian Pac J Cancer Prev, 11, 537-8.

Kumar Y, Mishra G, Gupta S, Shahtri S, (2011). Cancer screening for women living in urban slums, acceptance and satisfaction. Asian Pac J Cancer Prev, 12,1681-5

Lee CH, Peng CY, Li RN, et al (2014). Risk evaluation for the development of cervical intraepithelial neoplasia: development and validation of risk-scoring schemes. Int $J$ Cancer, 10, 1002

Lynge E, Rygaard C, Baillet MV, et al (2014). Cervical cancer screening at crossroads. APMIS, 122, 667-73.

Miller AB (2000). Report on consensus conference on cervical cancer screening and management. Int J Cancer, 86, 440447.

Misra JS, Gupta HP, Das V (2004). Assessing the feasibility of single life time screening pap smear evaluation between 41-45 years of age as strategy for cervical cancer control in developing countries: Our 32 years of experience of hospital based routine cytological screening. Diag Cytopath, 31,3769 .

Misra JS, Srivastava S, Singh U, Srivastava AN (2007). Risk factors and strategies for control of carcinoma cervix in India. Hospital based cytological screening of 35 years. Ind J Cancer, 48, 155-9.

Misra JS, Chhavi Singh M, Srivastava AN, Das V (2009). Assessment of potential of AgNOR counts as tumor markers in cervical carciogenesis. Diag Cytopath, 36, 194-5.

Prabhakar K (1992). Strategy for control of cervical cancer in India. Acta University Tamperensis. Ser. A:334:1-12.

Rowlands DC (1988). Nucleolar organizing regions in cervical intraepithelial neoplasia. J Clin Path, 41,1200-2

Srivastava AN, Srivastava S, Bansal C, Misra JS (2013). Diagnostic importance of AgNOR pleomorphism in cervical carcinogenesis. Ecancermedicalscience, 7, 287.
Thulaseedharan JV, Malila N, Hukama M, et al (2012) Sociodemographic and reproductive risk factors for cervical cancer- A large prospective cohort study from rural India. Asian Pac J Cancer Prev, 13, 2991-5.

Yasmeen J, Kureshi MA, Manzoor A, et al (2010). A community based screening of cervical cancer in a low prevalence area of India: A cross sectional study. Asian Pac J Cancer Prev, 11, 231-4. 